\title{
Article
}

\section{The Role of Societal Aspects in the Formation of Official COVID-19 Reports: A Data-Driven Analysis}

\author{
Marcell Tamás Kurbucz ${ }^{1,2,3, *,+} \mathbb{D}$, Attila Imre Katona ${ }^{1,+} \mathbb{D}^{\mathbb{D}}$, Zoltán Lantos ${ }^{4,5,+} \mathbb{D}$ and Zsolt Tibor Kosztyán ${ }^{1,3,5,6,+}$ \\ 1 Department of Quantitative Methods, Faculty of Business and Economics, University of Pannonia, \\ Egyetem Street 10, H-8200 Veszprém, Hungary; katona.attila@gtk.uni-pannon.hu (A.I.K.); \\ kosztyan.zsolt@gtk.uni-pannon.hu (Z.T.K.) \\ 2 Wigner Research Centre for Physics, Department of Computational Sciences, \\ Konkoly-Thege Miklós Street 29-33, H-1121 Budapest, Hungary \\ 3 Research Centre of Faculty of Business and Economics, University of Pannonia, Egyetem Street 10, \\ H-8200 Veszprém, Hungary \\ 4 Health Experience Institue, Közraktár Street 30-32, H-1093 Budapest, Hungary; zoltan.lantos@iask.hu \\ 5 Institute of Advanced Studies (iASK), Chernel Street 14., H-9730 Kőszeg, Hungary \\ 6 MTA-PE Budapest Ranking Research Group, Egyetem Street 10., H-8200 Veszprém, Hungary \\ * Correspondence: kurbucz.marcell@gtk.uni-pannon.hu \\ + These authors contributed equally to this work.
}

Citation: Kurbucz, M.T.; Katona, A.I Lantos, Z.; Kosztyán, Z.T. The Role of Societal Aspects in the Formation of Official COVID-19 Reports: A Data-Driven Analysis. Int. J. Environ. Res. Public Health 2021, 18, 1505. https://doi.org/10.3390/ ijerph18041505

Academic Editor: Carlos de las Heras-Pedrosa

Received: 6 January 2021

Accepted: 1 February 2021

Published: 5 February 202

Publisher's Note: MDPI stays neutral with regard to jurisdictional claims in published maps and institutional affiliations.

Copyright: (c) 2021 by the authors. Licensee MDPI, Basel, Switzerland. This article is an open access article distributed under the terms and conditions of the Creative Commons Attribution (CC BY) license (https:/ / creativecommons.org/licenses/by/ $4.0 /)$.

\begin{abstract}
This paper investigates the role of socioeconomic considerations in the formation of official COVID-19 reports. To this end, we employ a dataset that contains 1159 pre-processed indicators from the World Bank Group GovData360 and TCdata360 platforms and an additional 8 COVID-19 variables generated based on reports from 138 countries. During the analysis, a rank-correlation-based complex method is used to identify the time- and space-varying relations between pandemic variables and the main topics of World Bank Group platforms. The results not only draw attention to the importance of factors such as air traffic, tourism, and corruption in report formation but also support further discipline-specific research by mapping and monitoring a wide range of such relationships. To this end, a source code written in $\mathrm{R}$ language is attached that allows for the customization of the analysis and provides up-to-date results.
\end{abstract}

Keywords: COVID-19; country reports; socioeconomic analysis; data-driven approach

\section{Introduction}

Research on the COVID-19 pandemic has grown rapidly since the outbreak of the disease; however, despite the enormous media attention on countries' reports, only a few articles address the number of officially reported cases and deaths as a social phenomenon. As many studies have pointed out, there is a significant discrepancy between the officially confirmed data and recently published estimates (see, e.g., [1,2]). However, what do these data reflect, beyond the true nature of the virus? Of the few articles dealing with this question, authors [3] examined the protective effect of BCG (Bacillus Calmette-Guérin) vaccine on COVID-19 infections and the death toll while using indicators such as the Human Development Index (HDI), per-capita GDP, and urban population percentage as additional control variables. Moreover, in line with [4], they applied the Corruption Perception Index (CPI) as a proxy for the reliability of reported COVID-19 data. Other authors [5] found that measures of globalization, related to the migrant stock and air travel, were positively associated with both total cases and deaths. Results [6] suggest that more equitable access to healthcare does indeed increase testing rates and lower the death rate. Authors in [7] showed that more democratic political institutions experienced deaths on a larger per-capita scale and sooner than did less democratic countries, and based on [8], the population size and government health expenditure are strongly related to COVID-19 cases. 
In contrast to these (mostly) discipline-specific studies, our goal is to map, analyze, and monitor a wide range of such relationships in time and space by applying a datadriven approach. To provide a deeper understanding of the role of societal aspects in the formulation of COVID-19 reports, we employ a rank-correlation-based complex method and a dataset that contains 1159 pre-processed indicators from the World Bank Group GovData360 and TCdata360 platforms and an additional 8 COVID-19 variables. The results not only draw attention to the importance of factors such as air traffic, tourism, and corruption in report formation but also support decision makers and discipline-specific research by providing a source code written in $\mathrm{R}$ language (in R Notebook) that allows for the customization of the analysis and provides up-to-date results.

The paper is organized as follows. Section 2 introduces the data and methodology used during the calculations. Section 3 presents and discusses the results. Section 4 contains the measurement error analysis of the results. Finally, Section 5 provides the conclusions and proposes future research directions.

\section{Data and Methodology}

\subsection{Joint Dataset of GovData360, TCdata360, and COVID-19 Reports}

This paper follows the steps of [9] when creating a linked database of governance, trade, and competitiveness indicators with COVID-19 reports. (To derive the up-to-date dataset, we use the author's $\mathrm{R}$ source code, which is publicly available at [10]). Former indicators were obtained from the GovData360 and TCdata360 platforms using the data360r (version: 1.0.8) R package [11]. From these platforms, only annual indicators from 2015 and later were collected, and their missing values were replaced with previous annual values in descending order by year until 2015. During pre-processing, indicators (columns) where the ratio of missing values exceeded $50 \%$ were filtered out. Then, the same filtration was applied above $25 \%$ in the case of countries (rows). Finally, highly correlated variables and variables with near-zero variances were removed, and the standardized form of the retained 1159 indicators was connected with 8 COVID-19 variables, generated on the basis of the official reports of 138 countries [12]. Note that auxiliary indicators measuring the number of data sources and standard error were also filtered out, and variables with nearzero variances were eliminated using the default settings of nearZeroVar function contained by the caret (version: 6.0-85) $\mathrm{R}$ package [13]. The presented data were compiled on 22 July 2020. Table 1 shows the description of the variables in the structure of the final dataset.

Table 1. Variable description.

\begin{tabular}{|c|c|c|c|c|}
\hline Note & Group & Description and Short Name of Variables & NA & Source \\
\hline$c^{*}$ & \multirow{2}{*}{ ID } & Country ID; $c^{*} \in\{1,2, \ldots, 138\}$. & $0 \%$ & $\mathrm{a}$ \\
\hline$r^{*}$ & & Region ID; $r^{*} \in\{1,2, \ldots, 5\}$. & $0 \%$ & $\mathrm{~b}$ \\
\hline$y_{1}$ & \multirow{4}{*}{$\begin{array}{l}\mathscr{D} \\
\mathscr{D} \\
\tilde{U}\end{array}$} & The number of days since the first case. (dyssincefstcase) & $0 \%$ & a \\
\hline$y_{2}$ & & The total number of cases per capita after 20 days from the first case. (cases20dysaftfst) & $0 \%$ & a \\
\hline$y_{3}$ & & The total number of cases per capita after 40 days from the first case. (cases $40 \mathrm{dysaftfst)}$ & $0 \%$ & a \\
\hline$y_{4}$ & & The total number of cases per capita after 60 days from the first case. (cases60dysaftfst) & $0 \%$ & a \\
\hline$y_{5}$ & \multirow{4}{*}{ 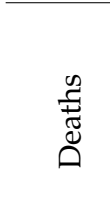 } & The number of days since the first death. (dyssincefstdeath) & $0 \%$ & a \\
\hline$y_{6}$ & & The total number of deaths per capita after 20 days from the first death. (deaths20dysaftfst) & $1 \%$ & a \\
\hline$y_{7}$ & & The total number of deaths per capita after 40 days from the first death. (deaths40dysaftfst) & $1 \%$ & a \\
\hline$y_{8}$ & & The total number of deaths per capita after 60 days from the first death. (deaths60dysaftfst) & $3 \%$ & a \\
\hline$x_{k}$ & Gov & \multirow{2}{*}{$\begin{array}{l}\text { The complete list of standardized GovData360 and TCdata360 indicators is } \\
\qquad \text { contained in the Supplementary Materials; } \\
\qquad k \in\{1,2, \ldots, 500\}, l \in\{501,502, \ldots, 1159\} .\end{array}$} & $5 \%$ * & c \\
\hline$x_{l}$ & TC & & $6 \% *$ & c \\
\hline
\end{tabular}

* Average missing value ratio. a: [12], the population data are from [14]. b: Own categories based on the country data of [12]. c: [11]. 


\subsection{Community-Based Model Reduction}

Our goal is to map the time- and space-varying relationship between COVID-19 (furthermore dependent) variables $\left(\mathcal{Y}:=\left\{y_{1}, . ., y_{M}\right\}\right)$ and indicators from GovData360 and TCdata360 platforms (furthermore independent variables, $\mathcal{X}:=\left\{x_{1}, . ., x_{N}\right\}$ ). To obtain an easily interpretable, comprehensive picture from these connections, similar GovData360 and TCdata360 indicators are grouped and characterized by latent variables. The applied steps are as follows.

First, standardized independent variables that have higher absolute (Spearman) rank correlation than an $\alpha$ parameter with at least one dependent variable are selected and denoted as $X \subseteq \mathcal{X}$. Formally:

$$
X:=\{x \mid x \in \mathcal{X} \wedge \exists y \in \mathcal{Y}, \text { where }|\operatorname{cor}(y, x)| \geq \alpha\} .
$$

Then, the rank correlation matrix of the selected variables is used as an adjacency matrix $\mathbf{A}$, in which absolute rank correlation values below a $\beta$ parameter are substituted by 0 . Formally:

$$
a_{i j}=[\mathbf{A}]_{i j}:=\left\{\begin{array}{cl}
0, & \text { if }\left|\operatorname{cor}\left(x_{i}, x_{j}\right)\right|<\beta \\
\left|\operatorname{cor}\left(x_{i}, x_{j}\right)\right|, & \text { if }\left|\operatorname{cor}\left(x_{i}, x_{j}\right)\right| \geq \beta
\end{array}, x_{i}, x_{j} \in X .\right.
$$

Note that the adjacency matrix A defines a network, where the vertices are the selected variables $(V=X)$, edges are indicated by the nonzero values $\left(e_{i j} \in E \Leftrightarrow[\mathbf{A}]_{i j}=a_{i j}>0\right)$, and their weight is the absolute rank correlation between the selected variables $(w: E \rightarrow$ $\mathbb{R}^{+}, w(i, j)=a_{i j}$ ). (Note that the same strategy was applied by, e.g., $[15,16]$, to visualize variable similarity.)

To group similar variables, our goal is to separate this network into groups of vertices that have fewer connections between them than inside the communities. In the literature, this task [17] is referred to as modularity-based community analysis (see, e.g., [18]) or simply community detection (see, e.g., [19]). Although the proposed method may seem more complicated than traditional model reduction methods, they cannot be used because of the large number of variables and relatively few observations. In addition, the visualization of the (correlation) network facilitates control over community formation (especially if $N$ is large). This benefit is realized by using the Louvain community detection method [20] with an associated filtrating procedure that gains heterogeneity between the groups by eliminating weakly connected group members.

After Louvain community detection, we obtain $C:=\left\{c_{1}, . ., c_{n}\right\}$ communities on $G(V, E)$, which specifies $\left\{G^{c_{1}}, . ., G^{c_{n}}\right\}=G$ partitions of network $G$. As a next step, each community is represented by a single composite (so-called latent) variable $\left(\hat{x}^{c_{i}}\right)$ obtained by the weighted linear combination of member variables:

$$
\hat{x}^{c_{i}}=\frac{\sum_{j} x_{j} e_{j}}{\sum_{j} e_{j}}, j \in V^{c_{i}}, i=1,2, . ., n,
$$

where

$$
e_{j}=\frac{1}{\lambda} \sum_{t \in V^{c_{i}}} a_{j t} e_{t}
$$

is the eigenvector centrality of node $j$, and $\lambda>0$ is a constant. Louvain modularity and eigenvector centrality were calculated using the cluster_louvain and eigen_centrality functions of igraph (version: 1.2.4.2) R package, respectively [21]. Note that the use of eigenvector centrality as a weight ensures that deeper embedded variables (within the given community) play a greater role in the formation of the latent variable. (Also note that the use of standardized independent variables results in standardized latent variables). To increase the homogeneity of communities, we calculate the absolute (Spearman) rank correlation of each variable within the community $i$ with the related latent variable $\hat{x}^{c_{i}}$, and variables that have weaker absolute rank correlation than a $\gamma$ parameter are removed 
from their communities. Finally, the steps of this paragraph (from community detection to filtration) are repeated until no more variables can be eliminated. Note that while the proposed algorithm finds strongly interrelated indicators, correlations between modules still can exist. Thus, completely independent communities are not guaranteed. Although the use of factor analysis with orthogonal rotation may result in independent communities, as there are more observations than variables in the studied dataset, the use of this method is not recommended.

At the end of the process, we rank communities (characterized by latent variables) by their absolute rank correlation with dependent variables. Then, we select the top $\mathcal{C} \leq n$ interpretable communities and investigate their relationship with the dependent variables through their absolute rank correlation coefficients. To examine the regional differences in addition to the study of time-varying relationships, these correlations are identified as well on the subset of different regions (see variable $r^{*}$ in Table 1). The calculation steps are summarized in Figure 1.

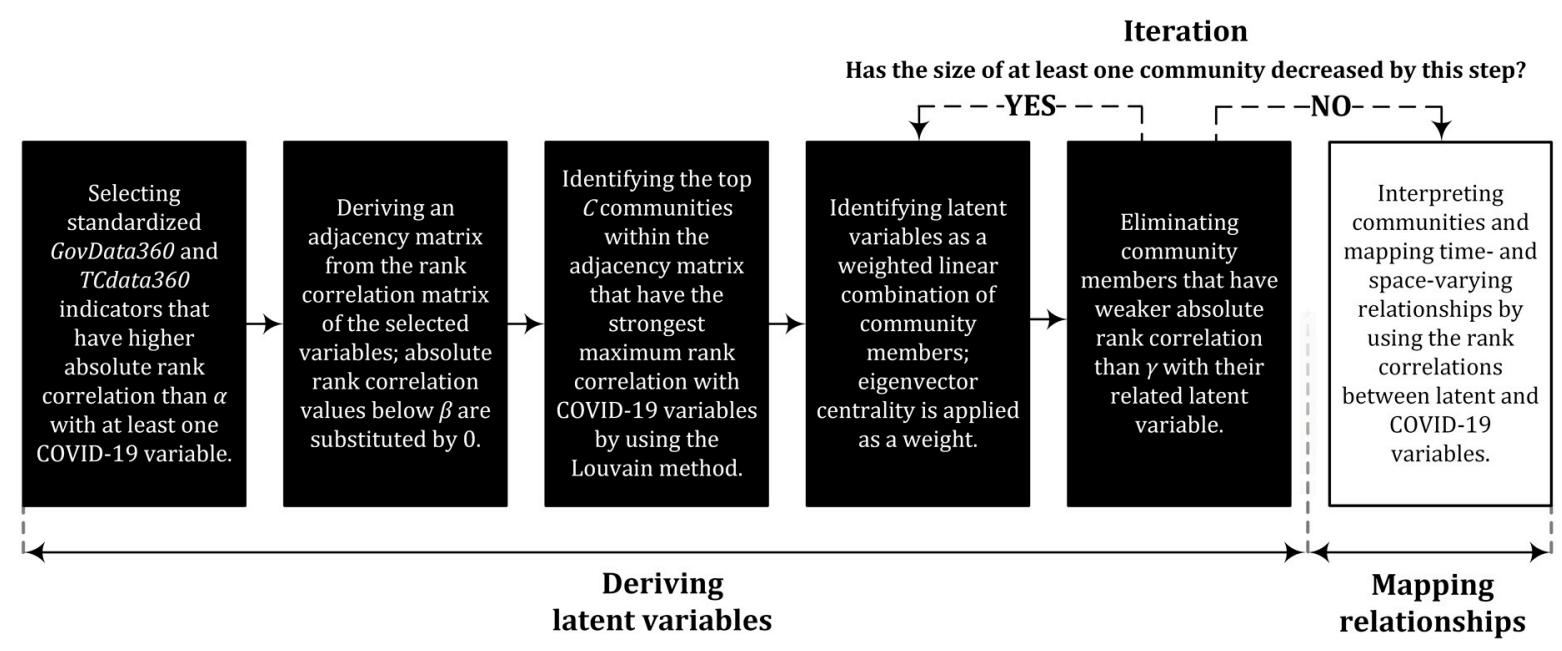

Figure 1. Calculation steps. The calculation process can be divided into six steps. The first five steps are responsible for creating communities characterized by latent variables, and the last one is about the interpretation of the communities and mapping their relationships with COVID-19 variables.

\section{Results and Discussion}

Following the calculation order presented above, we first illustrate and interpret the results of community detection to identify the most important topics reflected in official COVID-19 reports. Then, we investigate the time- and space-varying relations of these communities with different pandemic variables.

\subsection{Topics Most Related to COVID-19 Reports}

When setting $\alpha, \beta$, and $\gamma$ parameters, our goal was to group the widest possible range of important GovData360 and TCdata360 indicators without obtaining communities that are difficult to interpret. To accomplish this goal, we set the parameters as $\alpha=0.535, \beta=0.828$, and $\gamma=0.770$, which resulted in a network containing 319 indicators (vertices) and 1669 edges, representing the strong correlations among the indicators. Figure 2 illustrates five communities $(\mathcal{C}=5)$ detected within this network and helps their interpretation with word clouds generated on the basis of the names of member indicators. Word clouds were constructed after text cleaning and pre-processing by using the wordcloud (version: 2.6) $\mathrm{R}$ package [22]. Since pre-processing was based on a frequency list of terms contained by the names of the indicators, overlapping terms may occur in the composed word clouds. For example, the term "infrastructure" is included in several indicator names such as Electricity and telephony infrastructure and Quality of air transport infrastructure, even though they relate to different aspects of infrastructure. 
3. Business \& ICT

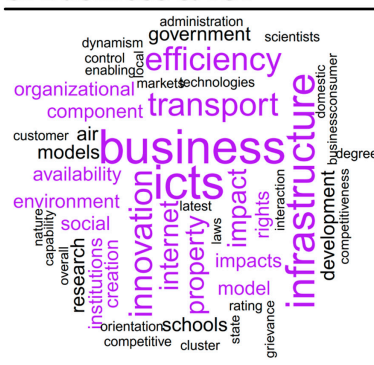

\section{Tourism \& Trade}

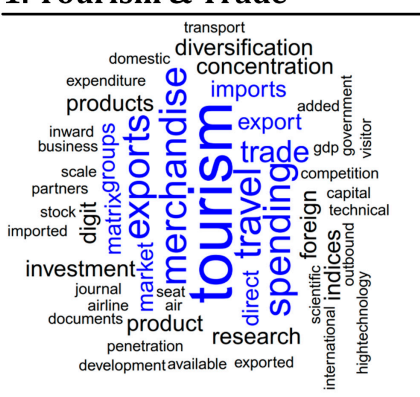

2. Infrastructure \& Digitalization

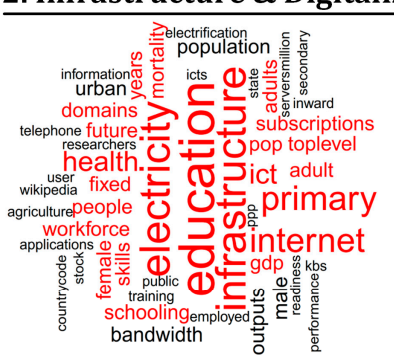

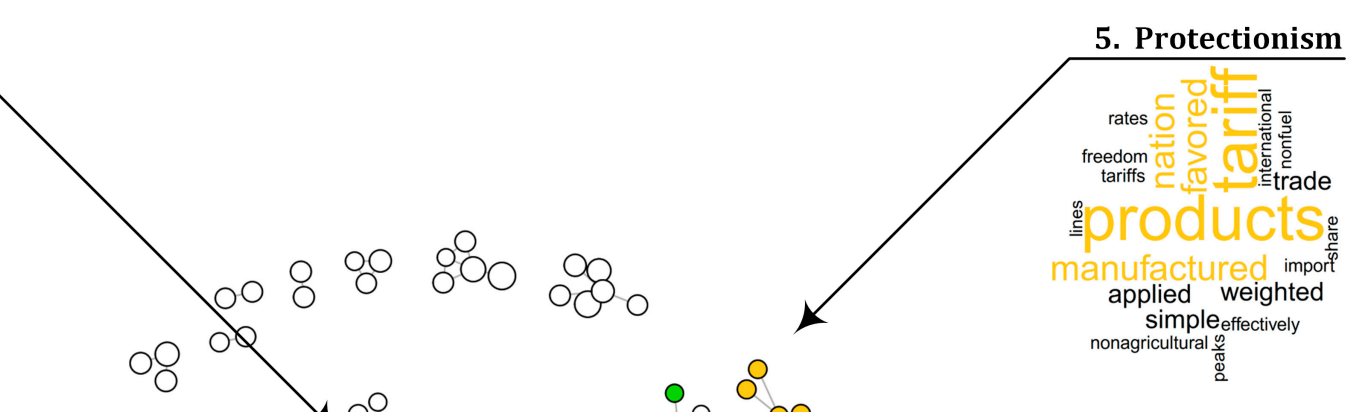

4. Regulation \& Corruption

Notations:

- Member variables eliminated by filtering:

- $\quad$ Maximum absolute rank correlation with COVID-19 variables: $\quad \begin{array}{llllll}0.50 & \bigcirc & 0.60 & \bigcirc & 0.75\end{array}$

Figure 2. Detected communities. The five communities of correlated GovData360 and TCdata360 indicators. Indicators are denoted by vertices and the edges representing the strong correlations among them. The interpretation of communities is supported by word clouds generated on the basis of the names of member indicators. Note that the applied method may not create purely separable communities, so the same words can occur in different word clouds. This can also occur if the same word appears in the names of significantly different indicators.

As Figure 2 shows, the topics most related to official COVID-19 reports are (1) tourism and trade, (2) infrastructure and digitalization, (3) business and ICT, (4) regulation and corruption, and (5) protectionism. From these, tourism and trade associates with the flow of people and goods, as reflected by the most frequent terms such as tourism, travel, merchandise, and imports. The contribution of the database also confirms this finding since most indicators of this community are part of the World Travel \& Tourism Council (27\%), United Nations Conference on Trade and Development Statistics (19\%), and World Integrated Trade Solution $(15 \%)$ datasets. The second community describes the infrastructure, especially in the field of digitalization, including variables such as ICT access, public services, and secure internet servers/million pop. Most of these variables are derived from the World Economic Forum Global Competitiveness Index (34\%), Global Innovation Index (24\%), and World Development Indicators (17\%) databases. The third community, so-called business and ICT, is adjacent to infrastructure and digitalization. As its name suggests, it is in connection with information and communication technology (ICT); however, this community focuses more on business aspects such as innovation, efficiency, and competitiveness. The group regulation and corruption includes variables such as regulatory quality, political environment, and corruption. The sources of most of these variables are the World Justice Project-Rule of Law (31\%), Global Innovation Index (25\%), and Global State of Democracy (19\%). Finally, the fifth community 
is labeled protectionism because all of its variables are related to tariffs. The variables for each community are detailed in the Supplementary Materials.

\subsection{Relations with COVID-19 Reports}

To visualize the absolute rank correlation between the COVID-19 variables and the communities characterized by latent variables, radar charts are employed. In Figure 3, these relations are classified into three groups. The first focuses on the time elapsed since the first registered data, while the other two relate to the officially reported cases and deaths per capita aggregated by using different time windows.

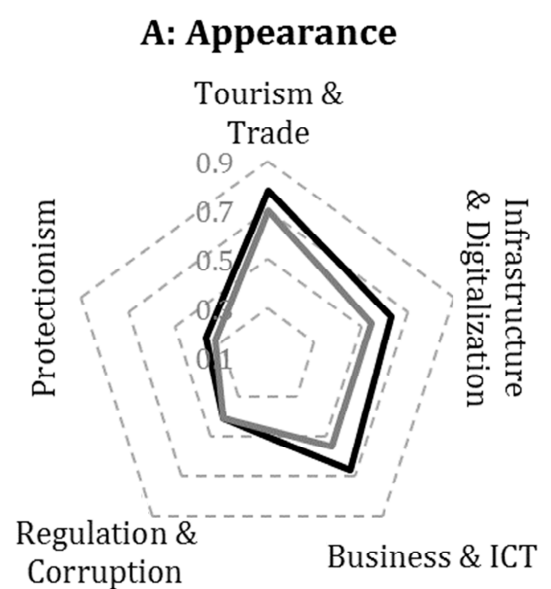

dyssincefstcase dyssincefstdeath
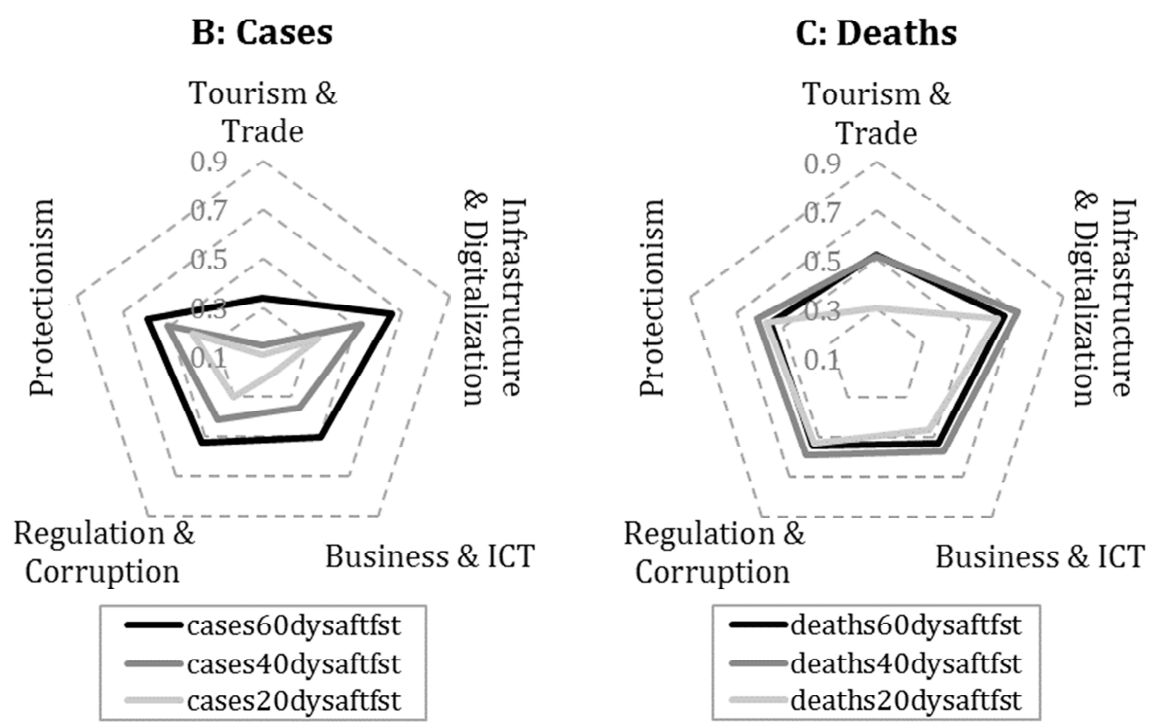

Figure 3. Absolute rank correlation between COVID-19 and latent variables. The correlations are presented according to the different COVID-19 variables related to the appearance of the virus (A), the number of cases (B), and the death toll (C).

As Figure 3 shows, indicators measuring the appearance of the virus are strongly correlated with tourism- and trade-related activities. Taking a closer look at the standalone variables within this community, GCI 4.0: Air transport and outbound travel and tourism expenditure have the strongest (Spearman) rank correlation coefficients with the days passed since the first case was reported (0.789 and 0.777, respectively). Moreover, this COVID-19 indicator has a strong connection with variables of international trade as well, such as Merchandise: Trade matrix by product groups, imports (0.755), Index Of Export Market Penetration (0.736), and Number of export partners (0.707) from the same community. In light of these close relationships, it may be surprising to find that this community has a relatively weak connection with the reported number of cases and deaths; however, increased controls at airports and the rapid closure of borders could be reflected in this result.

In contrast to tourism and trade, these COVID-19 indicators are closely linked to the other four communities, especially to infrastructure and digitalization. From this community, variables related to digital development such as fixed broadband subscriptions (per 100 people) and online creativity show the strongest positive (Spearman) rank correlation with the number of deaths per capita ( 0.659 and 0.653 , using the 60-day time window), which suggests that a significantly higher death toll has been reported by more developed countries. It is also reflected by the positive correlation of this COVID-19 variable with $A$. Health indicator calculated from healthy life expectancy $(0.582)$ as well as by its strong negative relationship with GCI 4.0: Exposure to unsafe drinking water (-0.676).

On the basis of these results, while the data suggesting the appearance of the virus seem to be reliable and relatively easy to explain, reports on cases and deaths appear highly distorted. On the one hand, this distortion may be a consequence of the poor health infrastructure that makes measurement difficult, but on the other hand, political interests 
could also be tied to underreporting. Since the regulation and corruption community's regulatory quality and freedom from corruption score indicators have a strong positive correlation with the reported number of cases ( 0.560 and 0.533 , respectively) and deaths $(0.565$ and 0.523 , respectively, using the 60-day time window), the reports of countries with higher levels of corruption seem much less authentic. Furthermore, detected communities contain strikingly many indicators related to the development of the information society, which counteracts disinformation.

To support discipline-specific research, we detailed the correlations of each member variable with different COVID-19 indicators in the Appendix A. These correlations can provide a deeper understanding of phenomenons mapped by using latent variables. For instance, the strongest correlations were found between the spread of the virus and the latent variable of the tourism and trade community. On the basis of Table A1, the strength of these relationships mainly is due to the indicators such as GCI 4.0: Air transport, International tourism and number of arrivals, and Outbound Travel \& Tourism Expenditure, or more generally, due to the number of inbound and outbound travels. Similar to latent variables (see Figure 3), these standalone indicators typically show increasing correlations with time window expansion; however, this change over time can vary significantly from region to region.

\subsection{Regional Differences}

To examine how the results presented in the previous subsection differ from region to region, countries are divided into four groups by using the region ID variable (denoted as $r^{*}$ in Table 1). These groups are Europe, Asia, Americas, Africa, and Oceania; however, the last group was omitted from the investigation due to its small sample size (two countries). The regional differences in the relations of COVID-19 and latent variables are presented in Figure 4.

On the basis of Figure 4, we can conclude that the impact of tourism and trade on the spread of the virus is significant regardless of region; however, the variable measuring the appearance of the first case shows the highest (Spearman) rank correlation with this community in the Americas and Europe. In these two regions, variables such as GCI 4.0: Air transport ( 0.803 and 0.791 , respectively) and government spending on travel and tourism service ( 0.881 and 0.715 , respectively) have one of the highest correlations with days elapsed since the first case. Moreover, in the Americas and Europe, this community, and especially its tourism- and air-transport-related indicators, shows an increasingly close relationship with the number of registered deaths per capita as the time window expands. Accordingly, regulations on foreign travel restrictions and airport controls are particularly important in these regions.

Next to the Americas and Europe, in Asia, variables measuring the spread of the virus are also strongly tied to the tourism and trade community, but these variables have a stronger rank correlation with the data related to first death. Unlike other regions, reports from Asian countries are mostly related to infrastructure and digitalization and protectionism communities; however, even these relations appear weak in comparison with the relationships detected in other regions. To obtain stronger ties, it may be worthwhile to map the topics that contain the most important variables separately for this region. 


\section{A: cases20dysaftfst}

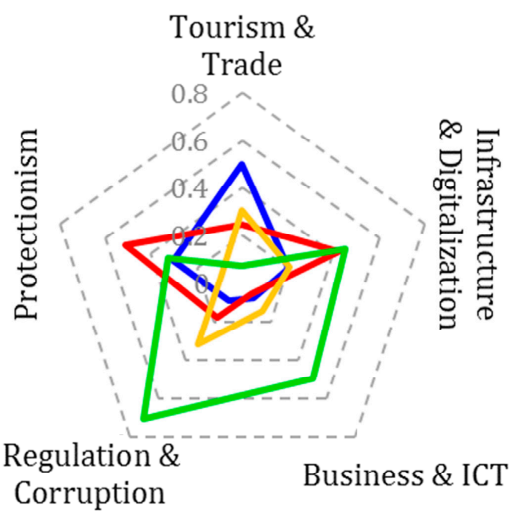

D: deaths20dysaftfst

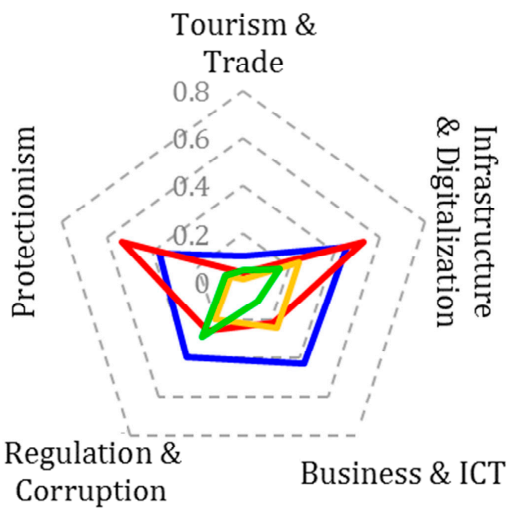

\section{G: dyssincefstcase}

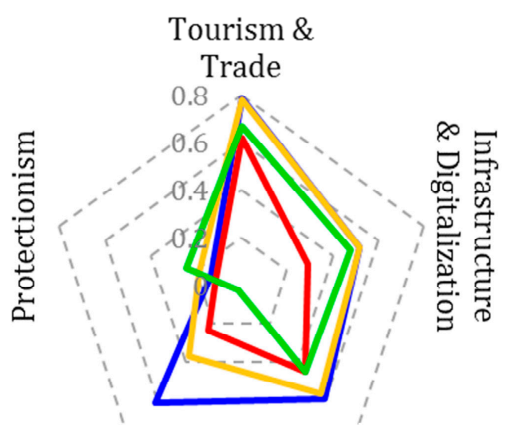

Regulation \& Corruption
B: cases40dysaftfst

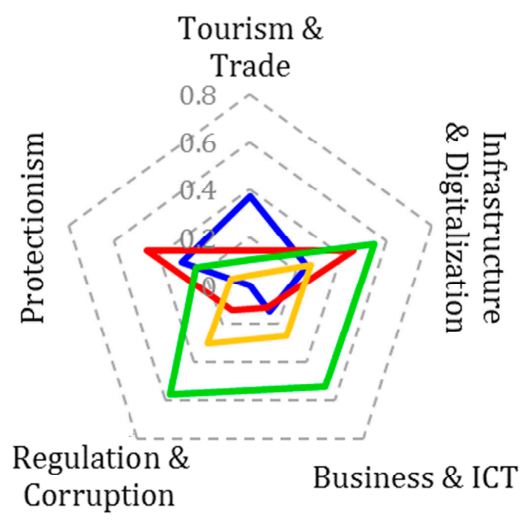

E: deaths40dysaftfst

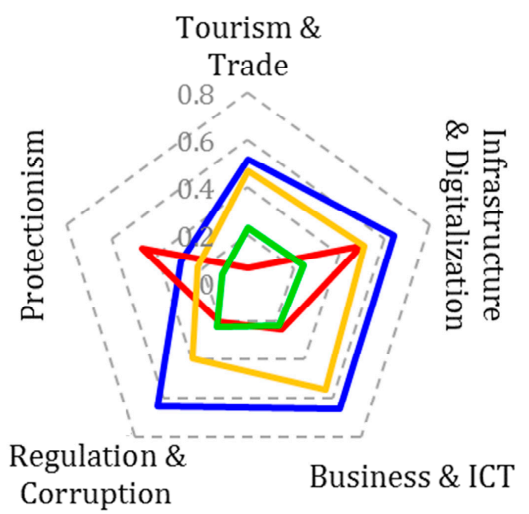

\section{H: dyssincefstdeath}

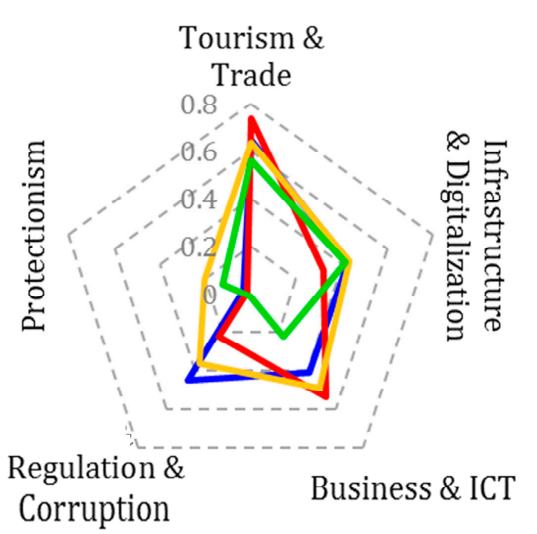

\section{C: cases60dysaftfst}

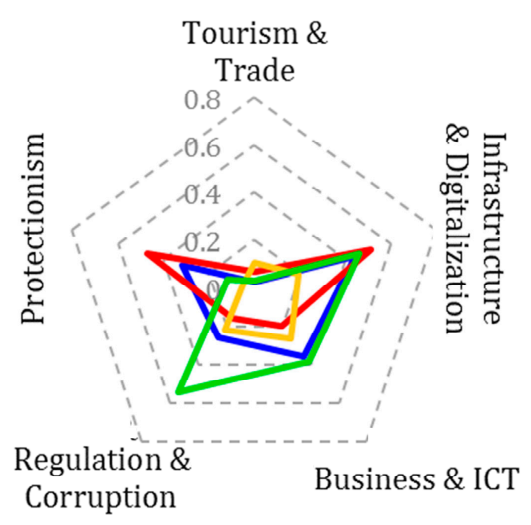

F: deaths60dysaftfst

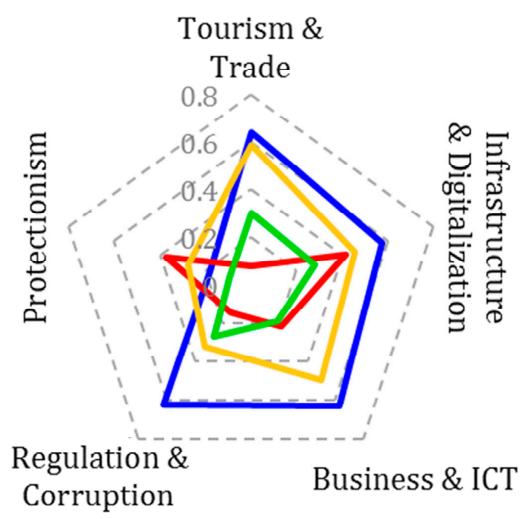

Figure 4. Absolute rank correlation between COVID-19 and latent variables by region. The correlations are presented according to the different COVID-19 variables that measure the total number of cases/deaths per capita after 20 days (A/D), 40 days $(\mathbf{B} / \mathbf{E})$, and 60 days $(\mathbf{C} / \mathbf{F})$ from the first case/death, as well as the number of days since the first case/death $(\mathbf{G} / \mathbf{H})$.

Finally, reported data both in Africa and Europe have remarkably close connections with the regulation and corruption community, especially with indicators such as political environment and freedom from corruption score. While in Africa these variables are typically related to reported case numbers ( 0.568 and 0.551), in Europe they show a stronger correlation with deaths ( 0.495 and 0.583 , using the 60 -day time window, respectively), which suggests that the reports of these regions are less credible. Note that the correlations of standalone variables calculated on different regional subsamples are contained in the Supplementary Materials. 


\section{Measurement Error Analysis}

As it was discussed in Section 3.2, while the data suggesting the appearance of the virus seem to be reliable and relatively easy to explain, reports on cases and deaths appear highly distorted. Since these measurement errors can affect the community detection outcomes through the distorted rank correlation coefficients, in this section, we conduct a simulation to analyze the validity of our results under the presence of measurement errors.

During the simulation, by using the multiplicative measurement error model, we added random measurement errors to the dependent variables and conducted all the calculation steps described by Figure 1. The applied measurement error model is as follows:

$$
y_{i}^{*}=y_{i} \varepsilon_{i}
$$

where the reported and the masked dependent variables are denoted by $y_{i}$ and $y_{i}^{*}$, and $\varepsilon_{i}$ is an independent random variable following a normal distribution with a mean 1 and standard deviation $\sigma_{\mathcal{\varepsilon}}$. During the simulation, $y_{i}^{*}$ was estimated by using different $\sigma_{\mathcal{\varepsilon}}$ values, then the resulted communities were examined. In order to characterize the structure of the communities we investigate the number of vertices and edges to the correlation network of the variables, number of communities found, and number of included variables in each community (see Table 2).

Table 2. Results of the measurement error analysis.

\begin{tabular}{|c|c|c|c|c|c|c|c|c|}
\hline \multirow{2}{*}{$\sigma_{\varepsilon}$} & \multicolumn{2}{|c|}{ Number of... } & \multirow{2}{*}{$\mathcal{C}$} & \multicolumn{5}{|c|}{ Size of Community... } \\
\hline & Vertices & Edges & & 1 & 2 & 3 & 4 & 5 \\
\hline $0.00 *$ & 321.0 & 1656.0 & 5.0 & 26.0 & 58.0 & 55.0 & 13.0 & 7.0 \\
\hline 0.01 & 313.7 & 1655.9 & 5.0 & 26.0 & 57.7 & 55.8 & 13.2 & 7.0 \\
\hline 0.03 & 309.5 & 1638.2 & 5.0 & 26.0 & 56.1 & 56.3 & 13.2 & 7.0 \\
\hline 0.05 & 298.5 & 1594.7 & 5.0 & 26.0 & 55.7 & 51.9 & 13.2 & 7.0 \\
\hline 0.10 & 275.8 & 1515.4 & 4.9 & 45.1 & 35.5 & 43.3 & 13.1 & 7.0 \\
\hline 0.15 & 202.7 & 1173.0 & 5.0 & 47.3 & 17.0 & 23.3 & 15.0 & 7.0 \\
\hline 0.20 & 208.3 & 1203.1 & 4.6 & 49.6 & 19.8 & 25.1 & 10.9 & 7.0 \\
\hline 0.30 & 186.0 & 1049.0 & 5.2 & 36.0 & 17.7 & 18.4 & 16.4 & 9.4 \\
\hline
\end{tabular}

Although number of extracted communities does not change significantly when $\sigma_{\varepsilon} \geq 0.1$, both the structure of the correlation network and the sizes of the communities start to vary. On the basis of this additional calculation, communities presented in Section 3.1 are stable in the event of a small or moderate measurement error.

\section{Conclusions and Future Work}

Although some of the recent studies have already investigated the relationship of COVID-19 data with different socioeconomic indicators, the role of societal considerations in the formation of official COVID-19 data is not yet clear. In contrast to these studies, our goal was to map, analyze, and monitor a wide range of such relationships in time and space by applying a data-driven approach. To this end, we employed a rank-correlation-based complex method and a dataset that contains 1159 pre-processed indicators from the World Bank Group GovData360 and TCdata360 platforms and an additional 8 COVID-19 variables generated on the basis of the officially reported number of cases and deaths.

From our results, the topics most related to official COVID-19 reports are tourism and trade, infrastructure and digitalization, business and ICT, regulation and corruption, and protectionism. By examining these topics and the variables they compress, we found that tourism- and air-transport-related variables are key factors in the spread of the virus, especially in the Americas and Europe. In these two regions, the variables of the tourism and 
trade community show close connections with the reported death toll as well, which also emphasizes the importance of regulations on foreign travel restrictions and airport controls. In addition, the number of reported cases and deaths seems unreliable since developed countries generally reported more cases and deaths than developing countries. In line with the results, the two possible reasons for underreporting may be the poor health infrastructure that makes measurement difficult and the political will that is opposed to exploring and presenting the real epidemiological situation. Accordingly, we experienced the closest relationship between the level of corruption and reported data in Europe and Africa.

Using the proposed analysis, further interesting regional and temporal patterns can be identified, as the data will be updated over time. To support this research, we attach an R Notebook file (see Supplementary Materials) that not only updates the dataset but is also able to conduct all the analysis steps, including variable filtering and the compilation of figures. As a further advantage, this source code can be easily customized and allows researchers to apply arbitrary time frames during the analysis. Finally, in the Appendix A, we provide all the relationships identified during the analysis to support discipline-specific investigations.

Supplementary Materials: The following are available online at www.mdpi.com/xxx/s1. File B.1: Metadata. The metadata of GovData360 and TCdata360 indicators used. File B.2: Regional correlations. Standalone correlations in the regional dataset. File B.3: Source of COVID-19 data. The source of the COVID-19 dataset collected by [13]. According to the place of their publication, these sources are websites of ministries of health $(43 \%)$, websites of public health institutes $(9 \%)$, websites from other national authorities $(6 \%)$, WHO websites, and WHO situation reports $(2 \%)$, and official dashboards $(10 \%)$. Besides, ECDPC screens social media accounts maintained by national authorities, for example Twitter, Facebook, YouTube, or Telegram accounts run by ministries of health (28\%) and other official sources (e.g., official media outlets) (2\%). File B.4: Data generation and analysis. Datasets were generated and analyzed with R Notebook, which can be used to update datasets and customize the analyses.

Author Contributions: Conceptualization, M.T.K. and A.I.K.; methodology, M.T.K., A.I.K. and Z.T.K.; software, M.T.K. and A.I.K.; validation, M.T.K., A.I.K., Z.L. and Z.T.K.; formal analysis, M.T.K. and A.I.K.; investigation, M.T.K., A.I.K., Z.L. and Z.T.K.; resources, M.T.K., A.I.K., Z.L. and Z.T.K.; data curation, M.T.K. and A.I.K.; writing-original draft preparation, M.T.K., A.I.K., Z.L. and Z.T.K.; writing - review and editing, M.T.K. and A.I.K.; visualization, M.T.K. and A.I.K.; supervision, M.T.K.; project administration, M.T.K.; funding acquisition, Z.T.K. All authors have read and agreed to the published version of the manuscript.

Funding: We acknowledge the financial support of Széchenyi 2020 under the EFOP-3.6.1-16-2016-00015.

Institutional Review Board Statement: Not applicable.

Informed Consent Statement: Not applicable.

Data Availability Statement: Data and source code are available in the Supplementary Material.

Conflicts of Interest: The authors declare no conflict of interest. 


\section{Appendix A. Standalone Correlations}

Table A1. Standalone correlations in the tourism and trade community. Spearman rank correlations between COVID-19 variables and indicators of the tourism and trade community in the worldwide dataset.

\begin{tabular}{|c|c|c|c|c|c|c|c|c|c|}
\hline Name & Type & 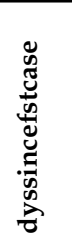 & 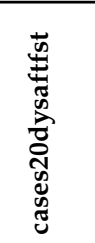 & 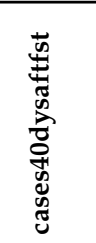 & 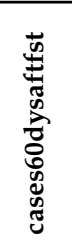 & 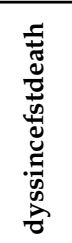 & 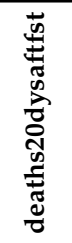 & 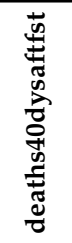 & 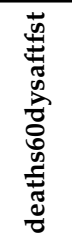 \\
\hline Trade, competition, \& market scale & rank* & 0.69 & -0.15 & 0.07 & 0.28 & 0.68 & 0.19 & 0.42 & 0.43 \\
\hline Scientific and technical journal articles & value & 0.77 & -0.19 & 0.07 & 0.25 & 0.69 & 0.20 & 0.43 & 0.44 \\
\hline Travel and Tourism direct contribution to GDP & usd nominal & 0.75 & -0.28 & -0.04 & 0.15 & 0.66 & 0.08 & 0.32 & 0.35 \\
\hline Outbound Travel \& Tourism Expenditure & usd nominal & 0.78 & -0.19 & 0.04 & 0.25 & 0.70 & 0.18 & 0.41 & 0.44 \\
\hline Index Of Export Market Penetration & value & 0.74 & -0.19 & 0.06 & 0.27 & 0.71 & 0.30 & 0.51 & 0.53 \\
\hline Merchandise: Trade matrix by product groups, imports & value & 0.76 & -0.27 & -0.01 & 0.20 & 0.67 & 0.16 & 0.40 & 0.41 \\
\hline Government spending on travel and Tourism service & usd nominal & 0.67 & -0.18 & 0.05 & 0.23 & 0.68 & 0.17 & 0.41 & 0.42 \\
\hline Capital investment in Travel and Tourism & usd real & 0.71 & -0.21 & -0.03 & 0.15 & 0.62 & 0.09 & 0.32 & 0.35 \\
\hline Services, etc., value added (current US\$) & value & 0.70 & -0.27 & -0.02 & 0.17 & 0.66 & 0.08 & 0.33 & 0.36 \\
\hline Business Tourism Spending & usd_nominal & 0.74 & -0.29 & -0.06 & 0.15 & 0.64 & 0.08 & 0.32 & 0.37 \\
\hline Number of export partners & value & 0.71 & -0.15 & 0.08 & 0.29 & 0.66 & 0.32 & 0.51 & 0.53 \\
\hline Foreign Direct Investment: Inward stock & percentage of world & 0.69 & -0.14 & 0.09 & 0.28 & 0.65 & 0.20 & 0.42 & 0.45 \\
\hline Domestic Tourism Spending & usd nominal & 0.70 & -0.36 & -0.12 & 0.08 & 0.63 & 0.04 & 0.29 & 0.34 \\
\hline Available airline seat & rank * & 0.76 & -0.22 & 0.00 & 0.20 & 0.64 & 0.11 & 0.33 & 0.35 \\
\hline High-technology exports (current US\$) & value & 0.69 & -0.14 & 0.08 & 0.27 & 0.63 & 0.25 & 0.45 & 0.45 \\
\hline Visitor Exports (Foreign spending) & usd real & 0.74 & -0.11 & 0.10 & 0.27 & 0.66 & 0.23 & 0.42 & 0.43 \\
\hline No. Of Imported HS6 Digit Products & value & 0.68 & -0.17 & 0.06 & 0.27 & 0.66 & 0.29 & 0.50 & 0.51 \\
\hline Citable documents $\mathrm{H}$ index & rank* & 0.71 & -0.19 & 0.06 & 0.25 & 0.67 & 0.25 & 0.47 & 0.49 \\
\hline No. Of Exported HS6 Digit Products & value & 0.65 & -0.13 & 0.10 & 0.30 & 0.64 & 0.32 & 0.51 & 0.52 \\
\hline GCI 4.0: Air transport & score & 0.79 & -0.07 & 0.16 & 0.35 & 0.66 & 0.28 & 0.47 & 0.46 \\
\hline International tourism, number of arrivals & value & 0.72 & -0.16 & 0.05 & 0.24 & 0.64 & 0.18 & 0.40 & 0.43 \\
\hline Research and development (R\&D) & rank* & 0.72 & 0.01 & 0.23 & 0.39 & 0.65 & 0.36 & 0.53 & 0.51 \\
\hline GCI 4.0: Research & rank * & 0.72 & 0.03 & 0.26 & 0.42 & 0.62 & 0.37 & 0.55 & 0.54 \\
\hline $\begin{array}{l}\text { Merchandise: Concentration and diversification } \\
\text { indices of exports by country }\end{array}$ & $\begin{array}{l}\text { diversification } \\
\text { index* }\end{array}$ & 0.63 & -0.04 & 0.18 & 0.34 & 0.60 & 0.39 & 0.56 & 0.53 \\
\hline Merchandise: Trade matrix by product groups, exports & value & 0.62 & -0.28 & -0.06 & 0.12 & 0.56 & 0.09 & 0.32 & 0.34 \\
\hline $\begin{array}{l}\text { Merchandise: Concentration and diversification } \\
\text { indices of imports by country }\end{array}$ & $\begin{array}{l}\text { diversification } \\
\text { index* }\end{array}$ & 0.67 & 0.00 & 0.23 & 0.42 & 0.64 & 0.38 & 0.57 & 0.58 \\
\hline
\end{tabular}

* The correlations of the rank variables and diversification indices were multiplied by -1 .

Table A2. Standalone correlations in the infrastructure and digitalization community. Spearman rank correlations between COVID-19 variables and indicators of the infrastructure and digitalization community in the worldwide dataset.

\begin{tabular}{|c|c|c|c|c|c|c|c|c|c|}
\hline Name & Type & 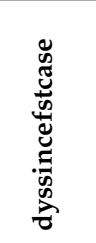 & 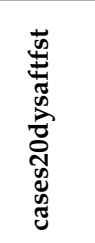 & 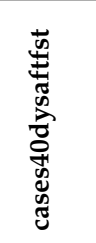 & 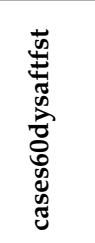 & 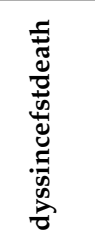 & 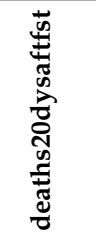 & 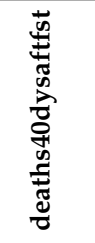 & 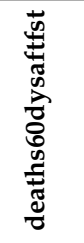 \\
\hline Public Services & score * & 0.59 & 0.38 & 0.53 & 0.65 & 0.49 & 0.60 & 0.67 & 0.61 \\
\hline ICT access & rank* & 0.59 & 0.38 & 0.54 & 0.65 & 0.51 & 0.63 & 0.69 & 0.62 \\
\hline $\begin{array}{l}\text { Country rank and value in the UNCTAD B2C } \\
\text { E-commerce Index }\end{array}$ & rank * & 0.61 & 0.30 & 0.46 & 0.59 & 0.52 & 0.59 & 0.67 & 0.61 \\
\hline 3rd pillar: Infrastructure & rank * & 0.56 & 0.33 & 0.49 & 0.62 & 0.50 & 0.60 & 0.69 & 0.64 \\
\hline Secure Internet servers/million pop. & rank * & 0.53 & 0.38 & 0.52 & 0.64 & 0.48 & 0.63 & 0.69 & 0.65 \\
\hline Fixed broadband subscriptions (per 100 people) & value & 0.56 & 0.30 & 0.50 & 0.61 & 0.53 & 0.61 & 0.71 & 0.66 \\
\hline GCI 4.0: Exposure to unsafe drinking water & score * & -0.57 & -0.34 & -0.53 & -0.66 & -0.53 & -0.64 & -0.72 & -0.68 \\
\hline GCI 4.0: 6.B Future workforce & score & 0.59 & 0.33 & 0.51 & 0.64 & 0.52 & 0.59 & 0.67 & 0.60 \\
\hline B. Readiness subindex & value & 0.61 & 0.30 & 0.49 & 0.62 & 0.51 & 0.60 & 0.69 & 0.63 \\
\hline B. Electricity and telephony infrastructure & rank* & 0.56 & 0.35 & 0.50 & 0.62 & 0.50 & 0.58 & 0.66 & 0.61 \\
\hline 5th pillar Higher education and training & value & 0.61 & 0.28 & 0.45 & 0.57 & 0.60 & 0.54 & 0.64 & 0.57 \\
\hline GDP per person employed (constant 2011 PPP \$) & value & 0.60 & 0.33 & 0.50 & 0.64 & 0.55 & 0.59 & 0.69 & 0.65 \\
\hline
\end{tabular}


Table A2. Cont.

\begin{tabular}{|c|c|c|c|c|c|c|c|c|c|}
\hline Name & Type & 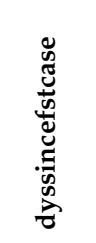 & 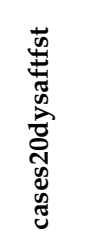 & 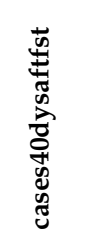 & 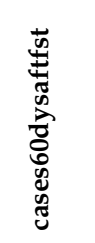 & 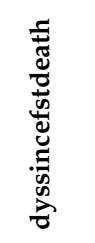 & 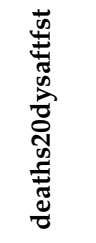 & 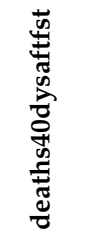 & 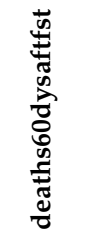 \\
\hline Infrastructure & rank* & 0.65 & 0.24 & 0.44 & 0.59 & 0.57 & 0.52 & 0.64 & 0.60 \\
\hline Information and communication technologies (ICTs) & score $(0-100)$ & 0.67 & 0.19 & 0.40 & 0.56 & 0.60 & 0.50 & 0.62 & 0.58 \\
\hline GCI 4.0: International co-inventions & score & 0.61 & 0.27 & 0.44 & 0.56 & 0.54 & 0.55 & 0.64 & 0.59 \\
\hline GCI 4.0: Pillar 2: Infrastructure & rank * & 0.71 & 0.20 & 0.43 & 0.59 & 0.61 & 0.54 & 0.66 & 0.62 \\
\hline 5th pillar: Skills & value & 0.58 & 0.32 & 0.47 & 0.59 & 0.51 & 0.57 & 0.63 & 0.56 \\
\hline GNI per capita (constant 2010 US\$) & value & 0.57 & 0.33 & 0.48 & 0.64 & 0.54 & 0.60 & 0.70 & 0.66 \\
\hline 4th pillar Health and primary education & value & 0.60 & 0.29 & 0.45 & 0.57 & 0.52 & 0.56 & 0.61 & 0.53 \\
\hline GCI 4.0: Internet users & rank * & 0.62 & 0.33 & 0.50 & 0.63 & 0.50 & 0.60 & 0.66 & 0.61 \\
\hline Wikipedia monthly edits & value & 0.50 & 0.34 & 0.54 & 0.67 & 0.51 & 0.69 & 0.75 & 0.71 \\
\hline GCI 4.0: Pillar 3: ICT adoption & rank * & 0.61 & 0.30 & 0.44 & 0.56 & 0.44 & 0.53 & 0.59 & 0.53 \\
\hline ICT PCT patents, applications/million pop. & rank * & 0.62 & 0.18 & 0.38 & 0.51 & 0.53 & 0.50 & 0.61 & 0.56 \\
\hline GCI 4.0: Electricity infrastructure & rank* & 0.65 & 0.28 & 0.46 & 0.56 & 0.52 & 0.52 & 0.57 & 0.50 \\
\hline Online creativity & score $(0-100)$ & 0.51 & 0.33 & 0.50 & 0.60 & 0.46 & 0.62 & 0.70 & 0.65 \\
\hline Researchers & rank* & 0.63 & 0.14 & 0.37 & 0.52 & 0.53 & 0.57 & 0.67 & 0.61 \\
\hline Mortality rate, adult, female (per 1000 female adults) & value & -0.65 & -0.35 & -0.53 & -0.65 & -0.55 & -0.60 & -0.66 & -0.61 \\
\hline Human capital and research & score $(0-100)$ & 0.62 & 0.18 & 0.35 & 0.50 & 0.54 & 0.49 & 0.61 & 0.56 \\
\hline Quality of electricity supply & $1-7$ best & 0.57 & 0.28 & 0.42 & 0.55 & 0.50 & 0.53 & 0.62 & 0.58 \\
\hline Legitimacy of the State & score * & 0.61 & 0.21 & 0.40 & 0.54 & 0.50 & 0.50 & 0.61 & 0.58 \\
\hline GCI 4.0: Mean years of schooling & rank* & 0.50 & 0.34 & 0.48 & 0.57 & 0.44 & 0.54 & 0.61 & 0.55 \\
\hline GCI 4.0: Trademark applications & score & 0.53 & 0.36 & 0.53 & 0.63 & 0.50 & 0.60 & 0.68 & 0.64 \\
\hline Generic top-level domains (gTLDs) & score $(0-100)$ & 0.49 & 0.33 & 0.48 & 0.59 & 0.51 & 0.58 & 0.68 & 0.63 \\
\hline Foreign Direct Investment: Inward stock & $\begin{array}{l}\text { usd per } \\
\text { capita }\end{array}$ & 0.42 & 0.43 & 0.54 & 0.63 & 0.37 & 0.60 & 0.63 & 0.58 \\
\hline GCI 4.0: Skills of future workforce & rank* & 0.57 & 0.32 & 0.48 & 0.60 & 0.48 & 0.55 & 0.60 & 0.52 \\
\hline Int'l Internet bandwidth, $\mathrm{kb} / \mathrm{s}$ per user & value & 0.48 & 0.38 & 0.53 & 0.65 & 0.47 & 0.62 & 0.70 & 0.67 \\
\hline GCI 4.0: Electrification rate & rank* & 0.57 & 0.35 & 0.53 & 0.61 & 0.50 & 0.60 & 0.66 & 0.59 \\
\hline Secondary education gross enrollment rate, \% & rank* & 0.52 & 0.31 & 0.52 & 0.65 & 0.52 & 0.59 & 0.67 & 0.63 \\
\hline Mean years of schooling & scale $(0$ to 1$)$ & 0.49 & 0.29 & 0.45 & 0.57 & 0.47 & 0.54 & 0.62 & 0.56 \\
\hline Fixed telephone subscriptions (per 100 people) & value & 0.48 & 0.36 & 0.52 & 0.62 & 0.51 & 0.60 & 0.67 & 0.63 \\
\hline Internet bandwidth & rank* & 0.46 & 0.43 & 0.54 & 0.62 & 0.40 & 0.62 & 0.66 & 0.61 \\
\hline Self-employed, total (\% of total employment) & percent & -0.50 & -0.35 & -0.46 & -0.60 & -0.40 & -0.56 & -0.63 & -0.60 \\
\hline School life expectancy & rank* & 0.50 & 0.25 & 0.45 & 0.58 & 0.50 & 0.58 & 0.67 & 0.63 \\
\hline Creative outputs & rank* & 0.59 & 0.24 & 0.42 & 0.53 & 0.51 & 0.49 & 0.60 & 0.54 \\
\hline Environmental performance & index & 0.53 & 0.29 & 0.48 & 0.60 & 0.54 & 0.57 & 0.66 & 0.61 \\
\hline Agriculture, value added ( $\%$ of GDP) & value & -0.46 & -0.34 & -0.46 & -0.60 & -0.42 & -0.54 & -0.61 & -0.58 \\
\hline A. Health & rank* & 0.59 & 0.30 & 0.48 & 0.60 & 0.57 & 0.55 & 0.62 & 0.58 \\
\hline Innovation Output Sub-Index & rank * & 0.63 & 0.13 & 0.33 & 0.46 & 0.54 & 0.46 & 0.59 & 0.56 \\
\hline GCI 4.0: Pupil-to-teacher ratio in primary education & score & 0.51 & 0.43 & 0.59 & 0.67 & 0.43 & 0.62 & 0.64 & 0.56 \\
\hline B. Primary education & rank* & 0.54 & 0.24 & 0.37 & 0.48 & 0.41 & 0.47 & 0.51 & 0.44 \\
\hline Health equality & scale $(0$ to 1$)$ & 0.51 & 0.32 & 0.45 & 0.58 & 0.41 & 0.54 & 0.58 & 0.52 \\
\hline Mortality rate, adult, male (per 1000 male adults) & value & -0.64 & -0.32 & -0.49 & -0.60 & -0.58 & -0.57 & -0.64 & -0.59 \\
\hline B. Primary education & value & 0.54 & 0.21 & 0.34 & 0.44 & 0.43 & 0.44 & 0.48 & 0.41 \\
\hline Country-code top-level domains (ccTLDs) & score $(0-100)$ & 0.41 & 0.31 & 0.48 & 0.58 & 0.42 & 0.57 & 0.65 & 0.60 \\
\hline Fertility rate, total (births per woman) & value & -0.55 & -0.30 & -0.47 & -0.55 & -0.50 & -0.58 & -0.64 & -0.58 \\
\hline Access to electricity ( $\%$ of population) & value & 0.60 & 0.35 & 0.53 & 0.62 & 0.53 & 0.56 & 0.63 & 0.58 \\
\hline Knowledge and technology outputs & rank* & 0.65 & 0.04 & 0.25 & 0.40 & 0.56 & 0.39 & 0.53 & 0.50 \\
\hline Access to electricity, urban (\% of urban population) & value & 0.65 & 0.29 & 0.47 & 0.55 & 0.52 & 0.51 & 0.58 & 0.52 \\
\hline
\end{tabular}

* The correlations of the rank and some score variables were multiplied by -1 . 
Table A3. Standalone correlations in the business and ICT community. Spearman rank correlations between COVID-19 variables and indicators of the business and ICT community in the worldwide dataset.

\begin{tabular}{|c|c|c|c|c|c|c|c|c|c|}
\hline Name & Type & 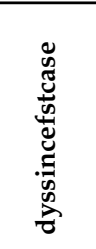 & 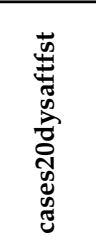 & 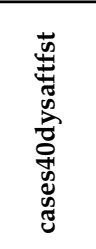 & 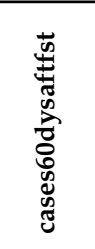 & 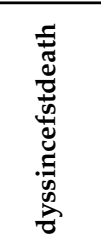 & 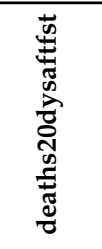 & 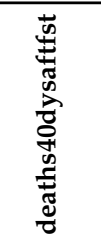 & 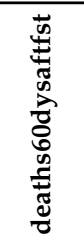 \\
\hline Global Competitiveness Index & value & 0.69 & 0.17 & 0.33 & 0.48 & 0.57 & 0.43 & 0.56 & 0.52 \\
\hline Laws relating to ICTs, $1-7$ (best) & value & 0.54 & 0.26 & 0.39 & 0.53 & 0.41 & 0.48 & 0.56 & 0.53 \\
\hline 9th pillar: Economic impacts & value & 0.61 & 0.23 & 0.41 & 0.55 & 0.54 & 0.52 & 0.63 & 0.59 \\
\hline Impact of ICTs on access to basic services, $1-7$ (best) & value & 0.56 & 0.26 & 0.39 & 0.52 & 0.41 & 0.48 & 0.55 & 0.50 \\
\hline 7th pillar: Business usage & rank* & 0.55 & 0.16 & 0.28 & 0.42 & 0.45 & 0.37 & 0.47 & 0.44 \\
\hline Availability of latest technologies, $1-7$ (best) & value & 0.52 & 0.27 & 0.40 & 0.53 & 0.44 & 0.53 & 0.60 & 0.56 \\
\hline GCI 4.0: Enabling environment component & rank* & 0.66 & 0.26 & 0.43 & 0.58 & 0.51 & 0.54 & 0.64 & 0.58 \\
\hline 10th pillar: Social impacts & value & 0.61 & 0.21 & 0.36 & 0.49 & 0.46 & 0.44 & 0.53 & 0.49 \\
\hline GCI 4.0: Pillar 1: Institutions & score & 0.56 & 0.26 & 0.40 & 0.51 & 0.43 & 0.47 & 0.54 & 0.48 \\
\hline Business-to-consumer Internet use, $1-7$ (best) & rank * & 0.65 & 0.14 & 0.31 & 0.45 & 0.51 & 0.41 & 0.54 & 0.51 \\
\hline Property rights score & value & 0.53 & 0.30 & 0.43 & 0.56 & 0.42 & 0.54 & 0.61 & 0.56 \\
\hline ICTs and business model creation & rank * & 0.63 & 0.11 & 0.31 & 0.46 & 0.54 & 0.40 & 0.52 & 0.49 \\
\hline GCI 4.0: Pillar 12: Innovation capability & rank* & 0.72 & 0.12 & 0.33 & 0.49 & 0.61 & 0.43 & 0.58 & 0.55 \\
\hline ICTs and organizational model creation & rank* & 0.65 & 0.08 & 0.26 & 0.41 & 0.51 & 0.37 & 0.50 & 0.47 \\
\hline 2nd pillar: Business and innovation environment & value & 0.54 & 0.32 & 0.44 & 0.57 & 0.43 & 0.54 & 0.61 & 0.54 \\
\hline $\begin{array}{l}\text { Impact of ICTs on new organizational models, 1-7 } \\
\text { (best) }\end{array}$ & value & 0.59 & 0.14 & 0.29 & 0.44 & 0.45 & 0.39 & 0.50 & 0.48 \\
\hline $\begin{array}{l}\text { ICT use for business-to-business transactions, } 1-7 \\
\text { (best) }\end{array}$ & value & 0.55 & 0.18 & 0.29 & 0.42 & 0.38 & 0.40 & 0.48 & 0.46 \\
\hline Internet access in schools, 1-7 (best) & value & 0.54 & 0.33 & 0.43 & 0.53 & 0.40 & 0.52 & 0.57 & 0.50 \\
\hline Impact of ICTs on business models, $1-7$ (best) & rank* & 0.57 & 0.17 & 0.32 & 0.46 & 0.47 & 0.41 & 0.50 & 0.48 \\
\hline Local supplier quality, 1-7 (best) & rank* & 0.55 & 0.20 & 0.38 & 0.53 & 0.59 & 0.51 & 0.62 & 0.56 \\
\hline Internet access in schools & $1-7$ best & 0.55 & 0.28 & 0.39 & 0.49 & 0.45 & 0.46 & 0.51 & 0.45 \\
\hline GCI 4.0: 1.F Property rights & score & 0.53 & 0.24 & 0.40 & 0.51 & 0.41 & 0.50 & 0.56 & 0.51 \\
\hline A. Transport infrastructure & value & 0.66 & 0.08 & 0.25 & 0.42 & 0.56 & 0.39 & 0.52 & 0.50 \\
\hline Value chain breadth, 1-7 (best) & rank * & 0.67 & 0.05 & 0.24 & 0.38 & 0.60 & 0.34 & 0.46 & 0.42 \\
\hline GCI 4.0: Interaction and diversity & rank* & 0.60 & 0.09 & 0.26 & 0.40 & 0.47 & 0.34 & 0.45 & 0.40 \\
\hline GCI 4.0: Markets component & score & 0.75 & 0.01 & 0.22 & 0.40 & 0.62 & 0.33 & 0.50 & 0.48 \\
\hline 12th pillar Innovation & rank* & 0.60 & 0.07 & 0.23 & 0.37 & 0.51 & 0.31 & 0.43 & 0.39 \\
\hline Quality of air transport infrastructure & rank* & 0.53 & 0.22 & 0.36 & 0.48 & 0.49 & 0.47 & 0.55 & 0.51 \\
\hline Quality of overall infrastructure & $1-7$ best & 0.55 & 0.24 & 0.37 & 0.49 & 0.47 & 0.47 & 0.55 & 0.50 \\
\hline Ease of doing business & $\mathrm{dtf}$ & 0.60 & 0.17 & 0.32 & 0.45 & 0.46 & 0.43 & 0.52 & 0.46 \\
\hline Country credit rating, $0-100$ (best) * & rank * & 0.64 & 0.14 & 0.30 & 0.48 & 0.54 & 0.44 & 0.57 & 0.54 \\
\hline GCI 4.0: Pillar 11: Business dynamism & rank* & 0.62 & 0.12 & 0.30 & 0.44 & 0.52 & 0.42 & 0.52 & 0.47 \\
\hline GCI 4.0: Efficiency of air transport services & rank * & 0.57 & 0.18 & 0.35 & 0.47 & 0.49 & 0.43 & 0.51 & 0.48 \\
\hline 8th pillar: Government usage & value & 0.59 & 0.11 & 0.25 & 0.39 & 0.41 & 0.33 & 0.41 & 0.39 \\
\hline GCI 4.0: Pillar 9: Financial system & rank * & 0.64 & 0.13 & 0.26 & 0.41 & 0.49 & 0.41 & 0.51 & 0.47 \\
\hline Control of international distribution, 1-7 (best) & rank* & 0.64 & 0.07 & 0.25 & 0.40 & 0.54 & 0.38 & 0.49 & 0.46 \\
\hline Quality of scientific research institutions & rank* & 0.58 & 0.10 & 0.27 & 0.40 & 0.54 & 0.37 & 0.50 & 0.46 \\
\hline A. Transport infrastructure & rank* & 0.72 & 0.05 & 0.29 & 0.46 & 0.59 & 0.41 & 0.56 & 0.54 \\
\hline Capacity for innovation & rank* & 0.55 & 0.04 & 0.19 & 0.32 & 0.50 & 0.25 & 0.37 & 0.33 \\
\hline Nature of competitive advantage, $1-7$ (best) & rank* & 0.54 & 0.15 & 0.26 & 0.37 & 0.43 & 0.34 & 0.41 & 0.36 \\
\hline GCI 4.0: Border clearance efficiency & score & 0.56 & 0.13 & 0.28 & 0.42 & 0.45 & 0.40 & 0.52 & 0.49 \\
\hline State of cluster development & rank * & 0.64 & -0.06 & 0.12 & 0.30 & 0.49 & 0.23 & 0.37 & 0.35 \\
\hline GCI 4.0: Quality of land administration & rank* & 0.51 & 0.28 & 0.44 & 0.53 & 0.43 & 0.50 & 0.56 & 0.52 \\
\hline Group Grievance & score & -0.54 & -0.18 & -0.32 & -0.49 & -0.51 & -0.44 & -0.56 & -0.53 \\
\hline GCI 4.0: 7.A Domestic competition & rank * & 0.55 & 0.10 & 0.25 & 0.39 & 0.42 & 0.31 & 0.40 & 0.35 \\
\hline Government Online Service Index, 0-1 (best) & rank* & 0.64 & 0.06 & 0.24 & 0.40 & 0.49 & 0.36 & 0.48 & 0.47 \\
\hline Company spending on Research \& Development & rank * & 0.57 & -0.02 & 0.12 & 0.26 & 0.48 & 0.21 & 0.34 & 0.31 \\
\hline GCI 4.0: Digital skills among population & rank* & 0.59 & 0.18 & 0.32 & 0.41 & 0.45 & 0.37 & 0.42 & 0.36 \\
\hline GCI 4.0: Efficiency of seaport services & rank* & 0.58 & 0.06 & 0.24 & 0.39 & 0.51 & 0.35 & 0.46 & 0.44 \\
\hline Getting electricity: Cost & $\begin{array}{l}\% \text { of income } \\
\text { per capita }\end{array}$ & -0.62 & -0.19 & -0.32 & -0.44 & -0.57 & -0.38 & -0.49 & -0.45 \\
\hline Degree of customer orientation, 1-7 (best) & value & 0.54 & 0.11 & 0.26 & 0.39 & 0.54 & 0.33 & 0.43 & 0.38 \\
\hline Use of virtual social networks, $1-7$ (best) & value & 0.55 & 0.26 & 0.38 & 0.47 & 0.43 & 0.50 & 0.53 & 0.48 \\
\hline $\begin{array}{l}\text { Registering property: Reliability of infrastructure } \\
\text { index }\end{array}$ & $0-8$ & 0.53 & 0.23 & 0.39 & 0.49 & 0.41 & 0.47 & 0.54 & 0.51 \\
\hline Availability of scientists and engineers & rank* & 0.64 & 0.00 & 0.17 & 0.29 & 0.57 & 0.26 & 0.39 & 0.34 \\
\hline A. Efficiency & value & 0.54 & 0.11 & 0.17 & 0.32 & 0.36 & 0.27 & 0.36 & 0.35 \\
\hline
\end{tabular}

* The correlations of the rank variables were multiplied by -1 . 
Table A4. Standalone correlations in the regulation and corruption community. Spearman rank correlations between COVID19 variables and indicators of the regulation and corruption community in the worldwide dataset.

\begin{tabular}{|c|c|c|c|c|c|c|c|c|c|}
\hline Name & Type & 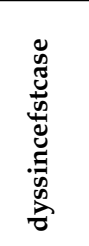 & 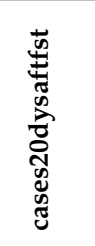 & 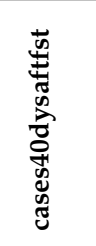 & 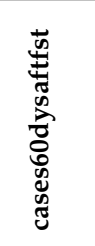 & 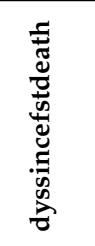 & 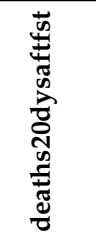 & 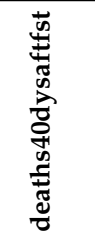 & 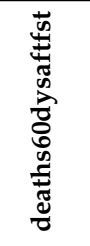 \\
\hline Regulatory quality & rank & 0.47 & 0.32 & 0.44 & 0.56 & 0.40 & 0.57 & 0.61 & 0.56 \\
\hline Political environment & ore $(0-100)$ & 0.42 & 0.33 & 0.41 & .52 & 0.33 & 0.53 & 0.56 & 0.51 \\
\hline Institutions & score $(0-100)$ & 48 & 0.31 & 0.42 & 53 & 0.39 & 0.52 & 0.58 & 0.52 \\
\hline Freedom from corruption score & value & 0.43 & 0.32 & 0.41 & 0.53 & 0.36 & 0.51 & 0.56 & 0.52 \\
\hline $\begin{array}{l}\text { Government officials in the police and the military do not } \\
\text { use public office for private gain }\end{array}$ & tot & 0.50 & 0.20 & 0.35 & 0.49 & 0.43 & 0.52 & 0.59 & 0.52 \\
\hline Due process of law and the rights of the accused & total & 0.46 & 0.23 & 0.40 & 0.55 & 0.45 & 0.55 & 0.62 & 0.56 \\
\hline $\begin{array}{l}\text { Government regulations are applied and enforced without } \\
\text { improper influence }\end{array}$ & total & 0.42 & 0.17 & 0.28 & 0.43 & 0.40 & 0.46 & 0.54 & 0.49 \\
\hline $\begin{array}{l}\text { The right to life and security of the person is effectively } \\
\text { guaranteed }\end{array}$ & total & 0.32 & 0.30 & 0.47 & 0.61 & 0.38 & 0.60 & 0.65 & 0.59 \\
\hline Corruption & scale $(0$ to 1$) *$ & -0.46 & -0.21 & -0.32 & -0.47 & -0.37 & -0.48 & -0.54 & -0.49 \\
\hline Regulatory environment & score $(0-100)$ & 0.36 & 0.26 & 0.36 & 0.45 & 0.25 & 0.49 & 0.55 & 0.50 \\
\hline Trading across borders: Time to import & days & -0.55 & -0.23 & -0.38 & -0.52 & -0.45 & -0.56 & -0.62 & -0.59 \\
\hline Civil Liberties & 1 to 7 scale * & 0.22 & 0.28 & 0.40 & 0.47 & 0.34 & 0.50 & 0.54 & 0.50 \\
\hline $\begin{array}{l}\text { Freedom from arbitrary interference with privacy is } \\
\text { effectively guaranteed }\end{array}$ & total & 0.38 & 0.19 & 0.39 & 0.54 & 0.42 & 0.52 & 0.59 & 0.54 \\
\hline Uneven Development & score & -0.29 & -0.28 & -0.39 & -0.47 & -0.38 & -0.48 & -0.55 & -0.52 \\
\hline Election government intimidation & scale $(0$ to 1$) *$ & -0.34 & -0.25 & -0.36 & -0.43 & -0.42 & -0.47 & -0.54 & -0.49 \\
\hline Election other voting irregularities & scale $(0$ to 1$) *$ & -0.42 & -0.23 & -0.34 & -0.45 & -0.40 & -0.47 & -0.55 & -0.51 \\
\hline
\end{tabular}

* The correlations of the rank and scale variables were multiplied by -1 .

Table A5. Standalone correlations in the protectionism community. Spearman rank correlations between COVID-19 variables and indicators of the protectionism community in the worldwide dataset.

\begin{tabular}{|c|c|c|c|c|c|c|c|c|c|}
\hline Name & Type & 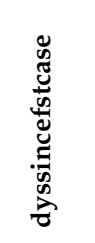 & 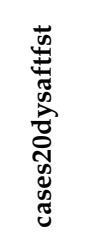 & 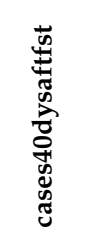 & 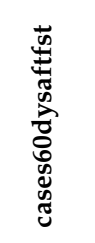 & 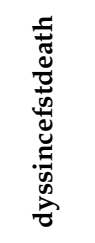 & 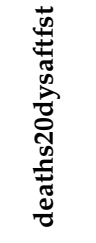 & 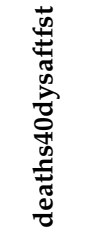 & 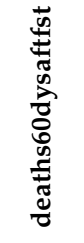 \\
\hline Tariff rate, applied, simple mean, all products (\%) & value & -0.28 & -0.39 & -0.48 & -0.54 & -0.29 & -0.52 & -0.55 & -0.50 \\
\hline $\begin{array}{l}\text { Tariff rate, most favored nation, weighted mean, manufactured } \\
\text { products }(\%)\end{array}$ & value & -0.40 & -0.35 & -0.45 & -0.54 & -0.35 & -0.50 & -0.56 & -0.51 \\
\hline GCI 4.0: Trade tariffs & rank & -0.30 & -0.36 & -0.47 & -0.56 & -0.30 & -0.52 & -0.56 & -0.51 \\
\hline $\begin{array}{l}\text { Tariff rate, most favored nation, simple mean, manufactured } \\
\text { products }(\%)\end{array}$ & value & -0.36 & -0.37 & -0.47 & -0.55 & -0.32 & -0.51 & -0.56 & -0.50 \\
\hline $\begin{array}{l}\text { Tariff rate, most favored nation, weighted mean, all products (\%) } \\
\text { Trade freedom score }\end{array}$ & $\begin{array}{l}\text { value } \\
\text { value }\end{array}$ & $\begin{array}{l}-0.37 \\
0.39\end{array}$ & $\begin{array}{l}-0.32 \\
0.34\end{array}$ & $\begin{array}{c}-0.46 \\
0.44\end{array}$ & $\begin{array}{c}-0.56 \\
0.51\end{array}$ & $\begin{array}{c}-0.35 \\
0.34\end{array}$ & $\begin{array}{l}-0.55 \\
0.53\end{array}$ & $\begin{array}{c}-0.61 \\
0.55\end{array}$ & $\begin{array}{l}-0.56 \\
0.49\end{array}$ \\
\hline $\begin{array}{l}\text { Effectively applied import tariff rates on non-agricultural and } \\
\text { non-fuel products }\end{array}$ & average & -0.34 & -0.33 & -0.42 & -0.47 & -0.36 & -0.52 & -0.56 & -0.49 \\
\hline $\begin{array}{l}\text { Share of tariff lines with international peaks, manufactured } \\
\text { products }(\%)\end{array}$ & value & -0.34 & -0.39 & -0.47 & -0.56 & -0.27 & -0.50 & -0.53 & -0.49 \\
\hline
\end{tabular}




\section{References}

1. Anastassopoulou, C.; Russo, L.; Tsakris, A.; Siettos, C. Data-based analysis, modelling and forecasting of the COVID-19 outbreak. PLoS ONE 2020, 15, e0230405. [CrossRef] [PubMed]

2. Modi, C.; Boehm, V.; Ferraro, S.; Stein, G.; Seljak, U. How deadly is COVID-19? A rigorous analysis of excess mortality and age-dependent fatality rates in Italy. medRxiv 2020. doi:10.1101/2020.04.15.20067074. [CrossRef]

3. Shivendu, S.; Chakraborty, S.; Onuchowska, A.; Patidar, A.; Srivastava, A. Is There Evidence that BCG Vaccination Has Non-Specific Protective Effects for COVID-19 Infections or Is It An Illusion Created by Lack of Testing? medRxiv 2020. [CrossRef]

4. Hollyer, J.R.; Rosendorff, B.P.; Vreeland, J.R. Measuring transparency. Political Anal. 2014, 413-434. [CrossRef]

5. Lim, V.V.X.; Prem, K.; Teo, A.K.J.; Tan, R.K.J. A Latent Class Analysis of COVID-19 Testing Response, Globalisation, and Democracy with National COVID-19 Outcomes: A Global Ecological Study. LANGLH-D-20-02931. 2020. Available online: https:/ / ssrn.com/abstract=3661324 (accessed on 4 February 2021).

6. Vadlamannati, K.C.; Cooray, A.; de Soya, I. Healthcare Equity and COVID-19; Working Paper 2020/89; WIDER: Helsinki, Finland, 2020.

7. Cepaluni, G.; Dorsch, M.; Branyiczki, R. Political Regimes and Deaths in the Early Stages of the COVID-19 Pandemic. Available online: https:/ /ssrn.com/abstract=3586767 (accessed on 4 February 2021).

8. Stojkoski, V.; Utkovski, Z.; Jolakoski, P.; Tevdovski, D.; Kocarev, L. The socio-economic determinants of the coronavirus disease (COVID-19) pandemic. arXiv 2020, arXiv:2004.07947.

9. Kurbucz, M.T. A Joint Dataset of Official COVID-19 Reports and the Governance, Trade and Competitiveness Indicators of World Bank Group Platforms; Data in Brief; Elsevier: Amsterdam, The Netherlands, 2020. [CrossRef]

10. Kurbucz, M.T. A Joint Dataset of Official COVID-19 Reports and the Governance, Trade and Competitiveness Indicators of World Bank Group Platforms. Mendeley Data, 2020. Available online: https:/ / data.mendeley.com/datasets/hzdnxph8vg/6 (accessed on 4 February 2021). doi:10.17632/HZDNXPH8VG.5. [CrossRef]

11. Ramin, R.; Onglao-Drilon, P. 'data360r': Wrapper for 'TCdata360' and 'Govdata360' API. R Package Version 1.0.8. R Package. 2020. Available online: https://cran.r-project.org/web/packages/data360r/index.html (accessed on 4 February 2021).

12. European Centre for Disease Prevention and Control. Today's Data on the Geographic Distribution of COVID-19 Cases Worldwide. Dataset, 2020. Available online: https:/ / opendata.ecdc.europa.eu/covid19/casedistribution/csv (accessed on 4 February 2021).

13. Kuhn, M. The Caret Package; R Package, R Foundation for Statistical Computing: Vienna, Austria, 2012. Available online: https: / / cran.r-project.org/package=caret (accessed on 4 February 2021).

14. World Bank Group. Dataset on the Total Population of Countries. Dataset, 2019. Available online: https://data.worldbank.org/ indicator/sp.pop.totl (accessed on 4 February 2021).

15. Sebestyén, V.; Bulla, M.; Rédey, Á.; Abonyi, J. Data-Driven Multilayer Complex Networks of Sustainable Development Goals; Data in Brief; Elsevier: Amsterdam, The Netherlands, 2019; Volume 25, p. 104049.

16. Sebestyén, V.; Bulla, M.; Rédey, Á.; Abonyi, J. Network model-based analysis of the goals, targets and indicators of sustainable development for strategic environmental assessment. J. Environ. Manag. 2019, 238, 126-135. [CrossRef] [PubMed]

17. Newman, M. Networks: An Introduction; OUP Oxford: Oxford, UK, 2010; Google-Books-ID: q7HVtpYVfC0C; ISBN 978-0-19-920665-0.

18. Gadár, L.; Kosztyán, Z.T.; Abonyi, J. The settlement structure is reflected in personal investments: Distance-dependent network modularity-based measurement of regional attractiveness. Complexity 2018, 2018. [CrossRef]

19. Tian, Y.; Gel, Y.R. Fusing data depth with complex networks: Community detection with prior information. Comput. Stat. Data Anal. 2019, 139, 99-116. [CrossRef]

20. Blondel, V.D.; Guillaume, J.-L.; Lambiotte, R.; Lefebvre, E. Fast unfolding of communities in large networks. J. Stat. Mech. Theory Exp. 2008, 2008, P10008. [CrossRef]

21. Csardi, G.; Nepusz, T. The igraph software package for complex network research. InterJournal Complex Syst. 2006, 1695, 1-9.

22. Fellows, I. Package 'Wordcloud'. R Package, Maintainer Ian and Rcpp, Linking To and Rcpp. 2018. Available online: https: / / cran.r-project.org/web/packages/wordcloud/wordcloud.pdf (accessed on 4 February 2021). 